\title{
Early versus Delayed Postoperative Oral Feeding after Gastrointestinal Anastomosis
}

\author{
Khaled Mohamed Sharaf, MD;1 Mohamed Attia M. Elsayed, MD;2 \\ Amr Mohamed M. Elhefny, MD. ${ }^{2}$
}

\section{1) Department of General Surgery, Zagazig University, Egypt. 2) Department of General Surgery, Ain Shams University, Egypt}

Background: There is no evidence that bowel rest and a period of starvation are beneficial for healing of gastrointestinal anastomosis.

Aim of work: This study assesses the outcomes of early oral feeding compared with the 5 days delay after small and large bowel anastomosis.

Patients and methods: This study included 40 patients with either small intestinal or colonic anastomosis randomly divided into two groups (20 patients each). Group I patients were managed traditionally with 5 day delay before oral feeding, while those of group II were allowed oral fluids once there was audible intestinal sounds or passage of flatus.

Results: There was no significant difference comparing both groups as regards gender and age distribution, cause and type of surgery and occurrence of intestinal fistula. There was a significant lower incidence of wound complications in group II with shorter hospital stay.

Conclusion: Early oral feeding after gastrointestinal anastomosis is safe, effective, well tolerated and beneficial to all patients.

Key words: Early feeding, delayed feeding, GIT anastomosis, flatus, TPN.

\section{Introduction:}

Adequate nutrition has always been a major goal of post operative care. However, because of ileus, early oral feeding after abdominal surgery is usually avoided and routine nasogastric tube decompression has been used instead. ${ }^{1}$

Traditionally, feeding for patients after gastrointestinal surgery started when flatus or defecation indicated the return of bowel function. IHowever, in recent years, early enteral nutrition in gastrointestinal surgery should be recommended whenever possible. ${ }^{2}$ Enteral nutrition (EN) has been shown to be of great importance in the management of the surgical patient it is preferred over total parenteral nutrition (TPN) for a number of reasons. Enteral access is easy, avoids the catheter infection associated with TPN and preserves gut immunity, integrity and motility. Bacterial translocation may also be diminished by this route of feeding. ${ }^{3}$ Early enteral nutrition in surgical patients has the advantages of reducing septic complications and overall morbidity when compared with parenteral nutrition. ${ }^{4}$

Early postoperative oral feeding is generally defined as liquid diet on either postoperative day 1 or 2 with advancement of the diet as tolerated. ${ }^{5}$

Early postoperative oral feeding has not been attempted after upper gastrointestinal anastomosis because of a fear of possible anastomotic leakage due to mechanical stimulation and the greater intraluminal pressure caused by early oral feeding after upper gastrointestinal anastomosis. ${ }^{6}$

The rationale of nil by mouth is to prevent postoperative nausea and vomiting and to protect the anastomosis, allowing time to heal before being stressed by food. ${ }^{7}$

There is no evidence that bowel rest and a period of starvation are beneficial for healing of wounds and anastomotic 
integrity. Indeed, the evidence is that luminal nutrition may enhance wound healing and increase anastomotic strength, particularly in malnourished patients. ${ }^{8}$

Patients undergoing surgery are at high risk of nutritional deficiency that can affect their clinical outcome, namely; length of hospital stay, rate of complications and mortality. This nutritional deficiency can be caused by increased resting energy expenditure by surgical injury and protein loss, However, the most important contributing factor is the lower intake of these patients immediately after surgery. Therefore, nutritional depletion is considered by many authors as an independent determinant of serious complications after major gastrointestinal surgery. ${ }^{9}$

\section{Patients and methods:}

Between March 2012 and April 2014, 40 patients undergoing open small intestinal and colonic anastomosis at Al-Azhar Hospital, Riyadh, Saudi Arabia and Ain Shams university hospitals in Cairo, Egypt were included in this study.

All patients were subjected to history assessment and clinical examination, blood samples were taken for routine laboratory investigation (CBC, liver function, renal function and serum electrolytes). The patients were also assessed radiologically by abdominal ultrasound, pelvic and abdominal $\mathrm{CT}$ and chest $\mathrm{X}$-ray.

The patients were then randomized into two groups; 20 patients each. Group I patients were managed traditionally by nasogastric insertion until intestinal sounds were audible and keeping them nothing by mouth until the $5^{\text {th }}$ day. On the $6^{\text {th }}$ day, the patient started oral fluids and on the $7^{\text {th }}$ day the patient took semisolids followed by regular diet. Group II patients were managed with no nasogastric tube insertion and began oral fluids on the $1^{\text {st }}$ postoperative day once there were audible intestinal sounds or passage of flatus and were advanced to a regular diet within the next 24$48 \mathrm{~h}$, as tolerated, indicated by absence of vomiting or abdominal distension.

The patients were monitored for vomiting, abdominal distension, length of hospitalization, postoperative surgical complications (wound infection, anastomotic leak, intraabdominal abscess, bowel obstruction) and readmission rate.

\section{Statistical analysis:}

Data were collected, coded, revised and entered to the Statistical package for social science (IBM SPSS) version 21. The data were presented as mean, standard deviations and ranges for the quantitative data with parametric distribution while frequencies and percentages were used to present the qualitative data. The comparison between groups with qualitative data was done by using Chi-square test and/or Fisher exact test instead of Chi-square only when the expected count in any cell found less than 5\%. The comparison between two independent groups with quantities data and parametric distribution was done by using independent t-test. The confidence interval was set to $95 \%$ and the margin of error accepted was set to $5 \%$. So, the P-value was considered significant as the following: $p>0.05$ : Non significant $(\mathrm{NS}) ; \mathrm{P}<0.05$ : significant $(\mathrm{S}) ; \mathrm{P}$ $<0.01$ : Highly significant (HS).

\section{Results:}

Group I included 17 males and 3 females. Their ages ranged from 35 to 50 years while group II included 16 males and 4 females, and their ages ranged from 30-50 years. There was no significant difference comparing the two groups as regards age and gender distribution.

Table (1) shows the distribution and type of resection of both small intestinal and colonic cases in both groups.

One patient (2.5\%) in group I and 2 patients in group II (5\%) were complicated with intestinal fistula with no significant difference between the two groups. One patient in each group had low output small intestinal fistula, which was managed conservatively by nasogastric tube insertion and total parenteral nutrition. The $2^{\text {nd }}$ case in group II, the patient presented by high output small intestinal fistula that was managed by re-exploration and revision of the anastomosis.

Nasogastric tube was used in a significantly 


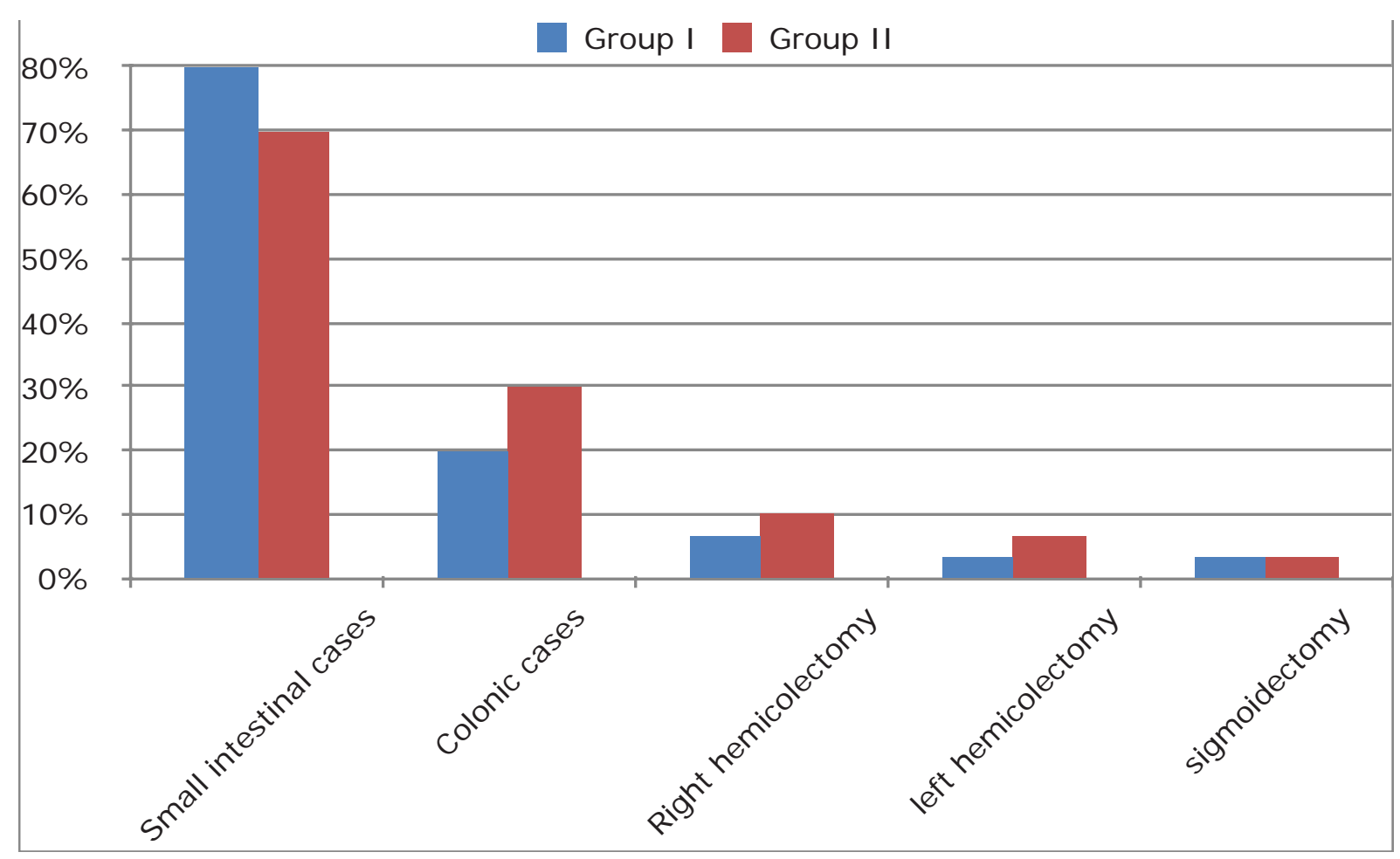

Figure (1): Distribution of both small intestinal and colonic cases.

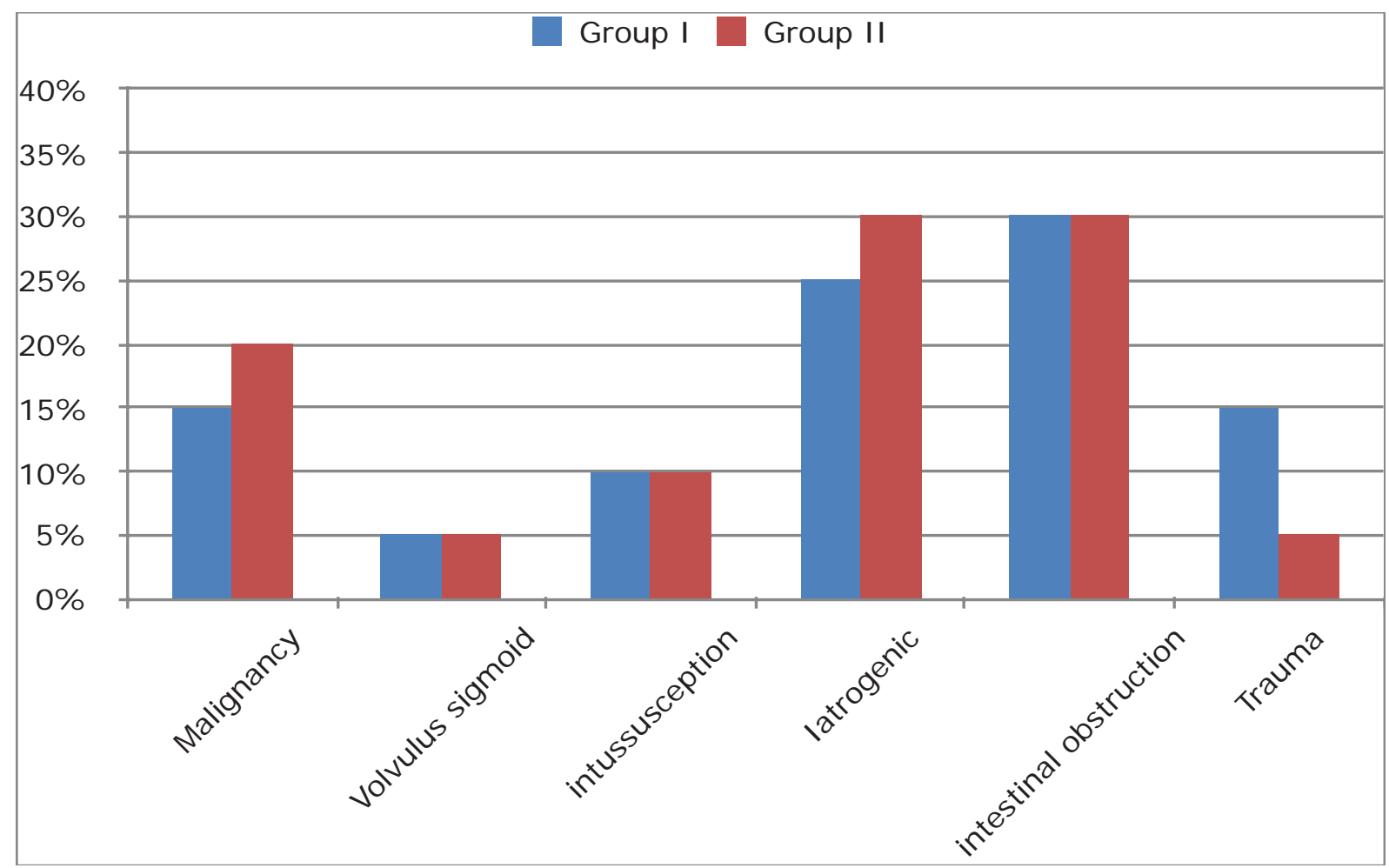

Figure (2): Underlying cause of surgical interference.

lower number of patients of group II (2 patients) while it has been used in all patients of group I, as shown in Table (3).

As shown in Table (4), wound complications showed significant difference between the two groups which was higher in group I than group II.

As regard hospital stay, the mean was 9 \pm 2.3 days (range of 8 - 21 days) in group I, which was significantly longer than in group II, mean of $5 \pm 1.6$ days (range of 3-15 days). Medical complications in the form of 


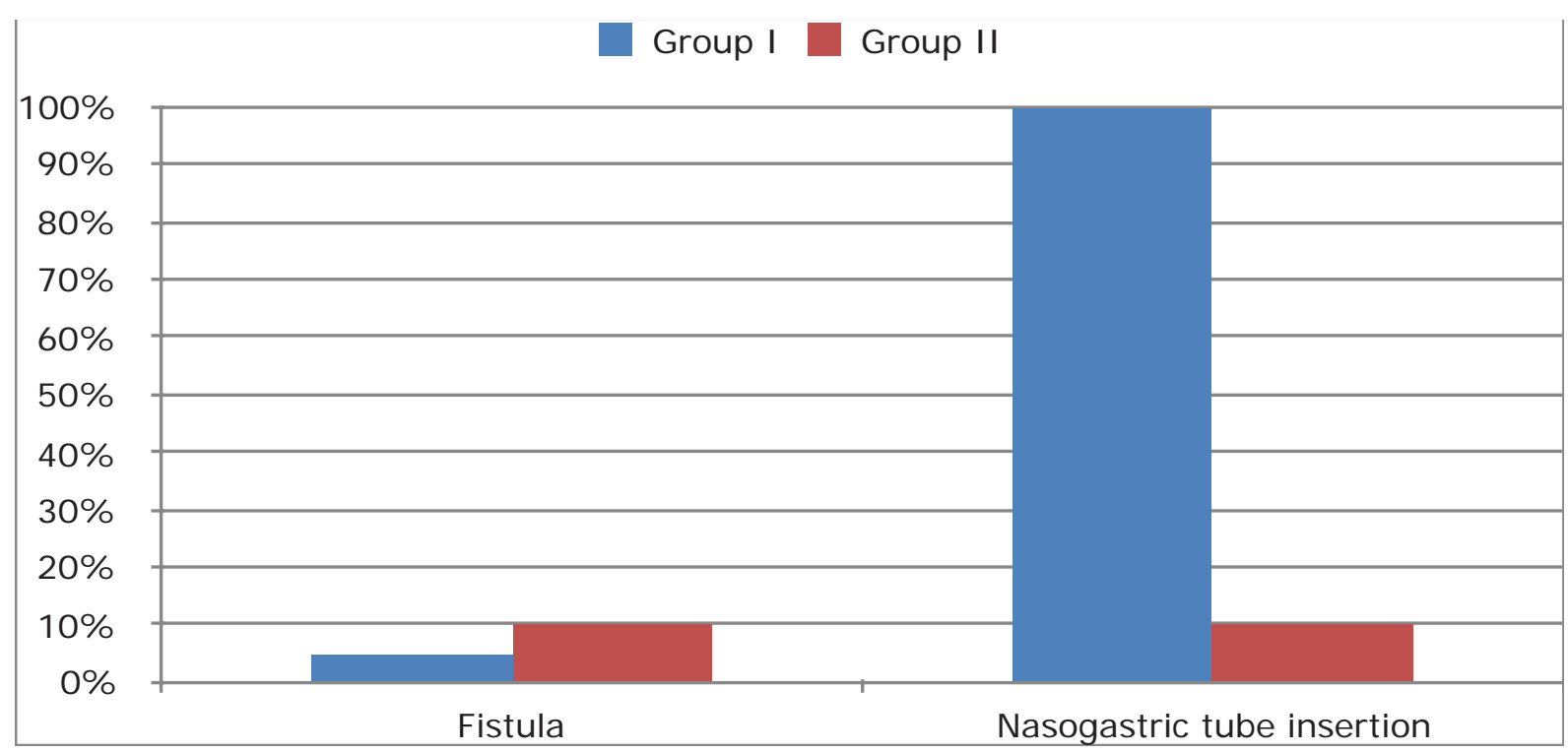

Figure (3): Fistula and nasogasteic tube insertion

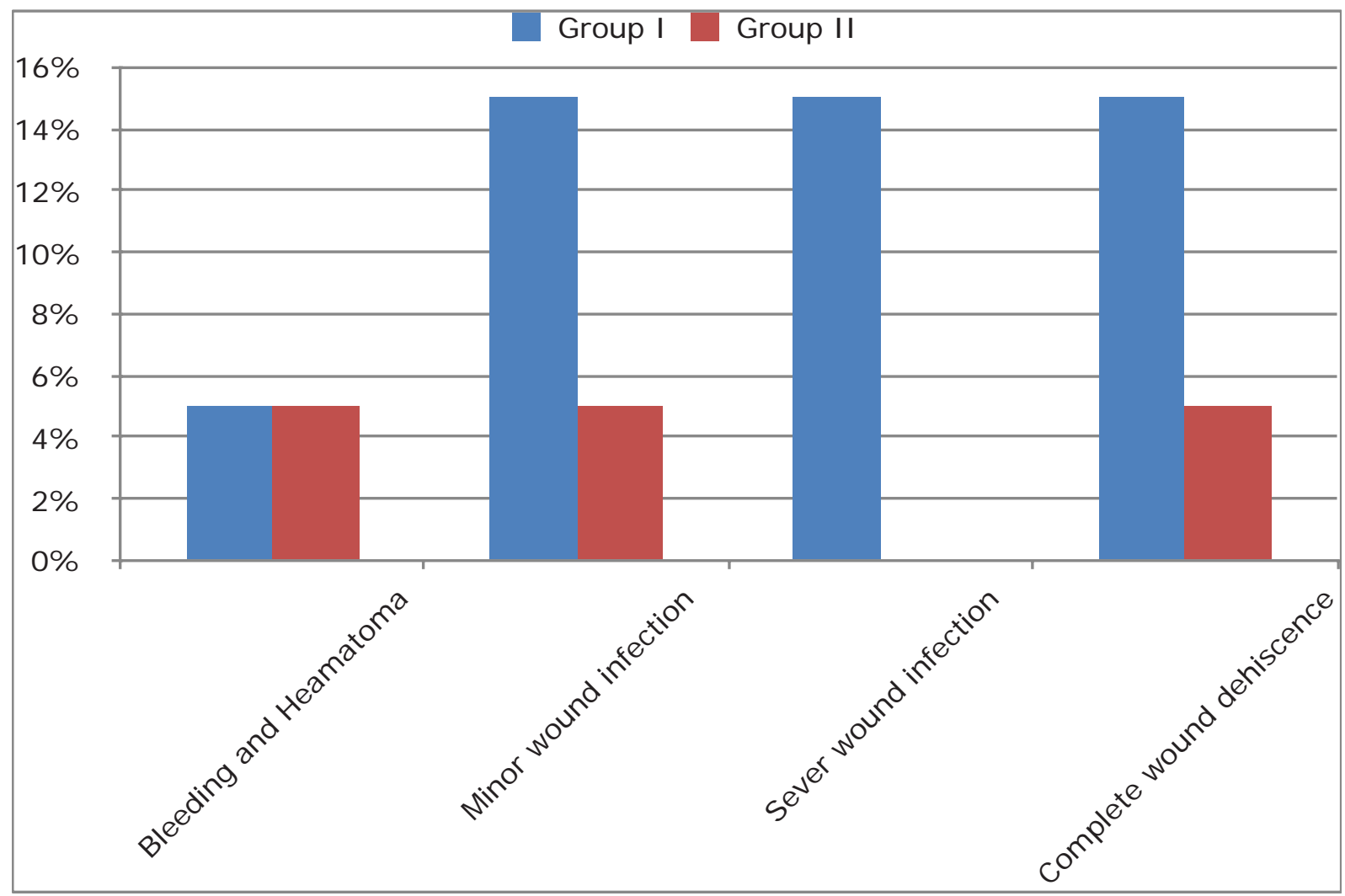

Figure (4): Wound complications.

aspiration pneumonia was higher in group I: 4 patients (10\%) than in group II : 1 patient (2.5\%).

\section{Discussion:}

The use of a nasogastric tube, fasting and intravenous solution were traditional methods in abdominal surgery postoperative management. However, there has been a trend toward earlier feeding in post-abdominal surgery patients in recent decades. The routine nasogastric tube decompression after abdominal and colorectal surgery has already been discussed. ${ }^{10}$

The gastrointestinal tract motility of patients undergoing abdominal surgery is transiently impaired (postoperative ileus, POI). Multiple factors are thought to contribute 
Table (1): Distribution of both small intestinal and colonic cases.

\begin{tabular}{|l|l|c|c|c|c|c|c|c|}
\hline \multirow{2}{*}{} & \multicolumn{2}{|c|}{ Total number } & \multicolumn{2}{c|}{ Group I } & \multicolumn{2}{c|}{ Group II } & \multicolumn{2}{c|}{ Chi-square test } \\
\cline { 2 - 9 } & No. & $\mathbf{\%}$ & No. & $\mathbf{\%}$ & No. & $\mathbf{\%}$ & X2 & P-value \\
\hline Small intestinal cases & 30 & $75.0 \%$ & 16 & $80 \%$ & 14 & $70 \%$ & \multirow{2}{*}{0.533} & \multirow{2}{*}{0.465} \\
\hline Colonic cases & 10 & $25.0 \%$ & 4 & $20 \%$ & 6 & $30 \%$ & & \\
\hline Right hemicolectomy & 5 & $12.5 \%$ & 2 & $6.7 \%$ & 3 & $10 \%$ & 0.229 & 0.632 \\
\hline left hemicolectomy & 3 & $7.5 \%$ & 1 & $3.3 \%$ & 2 & $6.7 \%$ & 0.36 & 0.548 \\
\hline sigmoidectomy & 2 & $5.0 \%$ & 1 & $3.3 \%$ & 1 & $3.3 \%$ & 0.000 & 1.000 \\
\hline
\end{tabular}

Table (2): Underlying cause of surgical interference in both groups.

\begin{tabular}{|l|l|l|l|l|l|l|l|l|}
\hline \multirow{2}{*}{ Underlying disease } & \multicolumn{2}{|c|}{ Total number } & \multicolumn{2}{c|}{ Group I } & \multicolumn{2}{c|}{ Group II } & \multicolumn{2}{c|}{ Chi-square test } \\
\cline { 2 - 10 } & No. & \% & No. & \% & No. & \% & X2 & p-value \\
\hline 1. Malignancy & 7 & $17.5 \%$ & 3 & $15 \%$ & 4 & $20 \%$ & 0.173 & 0.677 \\
\hline 2. Volvulus sigmoid & 2 & $5 \%$ & 1 & $5 \%$ & 1 & $5 \%$ & 0.000 & 1.000 \\
\hline 3. intussusception & 4 & $10 \%$ & 2 & $10 \%$ & 2 & $10 \%$ & 0.000 & 1.000 \\
\hline $\begin{array}{l}\text { 4. Iatrogenic (during caesarian } \\
\text { section) }\end{array}$ & 11 & $27.5 \%$ & 5 & $25 \%$ & 6 & $30 \%$ & 0.125 & 0.724 \\
\hline 5. Intestinal obstruction & 12 & $30 \%$ & & $30 \%$ & & & 0.000 & 1.000 \\
\hline a. Meckle's diverticulitis & 4 & $10 \%$ & 2 & $10 \%$ & 2 & $10 \%$ & 0.000 & 1.000 \\
\hline b. Adhesive band & 5 & $12.5 \%$ & 3 & $15 \%$ & 2 & $10 \%$ & 0.229 & 0.632 \\
\hline c. Phytobezoars & 3 & $7.5 \%$ & 1 & $5 \%$ & 2 & $10 \%$ & 0.360 & 0.548 \\
\hline 6. Trauma & 4 & $10 \%$ & 3 & $15 \%$ & 1 & $5 \%$ & 0.000 & 1.000 \\
\hline
\end{tabular}

Table (3): Fistula and nasogastric tube insertion.

\begin{tabular}{|l|l|l|l|l|l|l|}
\hline \multirow{2}{*}{} & \multicolumn{2}{|c|}{ Total } & \multicolumn{2}{c|}{ Group I } & \multicolumn{2}{c|}{ Group II } \\
\cline { 2 - 7 } & No. & $\mathbf{\%}$ & No. & \multicolumn{1}{c|}{$\%$} & No. & $\mathbf{\%}$ \\
\hline Fistula & 3 & $7.5 \%$ & 1 & $5 \%$ & 2 & $10 \%$ \\
\hline Nasogastric tube insertion & 22 & $55 \%$ & 20 & $100 \%$ & 2 & $10 \%$ \\
\hline
\end{tabular}

Table (4): Wound complications.

\begin{tabular}{|l|l|l|c|c|c|c|c|c|}
\hline \multirow{2}{*}{} & \multicolumn{2}{|c|}{ Total } & \multicolumn{2}{c|}{ Group I } & \multicolumn{2}{c|}{ Group II } & \multicolumn{2}{c|}{ Chi-square test } \\
\cline { 2 - 10 } & No. & \% & No. & \% & No. & \% & X2 & p-value \\
\hline Bleeding and Heamatoma & 2 & $5 \%$ & 1 & $5 \%$ & 1 & $5 \%$ & 0.000 & 1.000 \\
\hline Minor wound infection & 4 & $10 \%$ & 3 & $15 \%$ & 1 & $5 \%$ & 1.111 & 0.292 \\
\hline Sever wound infection & 3 & $7.5 \%$ & 3 & $15 \%$ & 0 & $0 \%$ & 3.243 & 0.072 \\
\hline Complete wound dehiscence & 4 & $10 \%$ & 3 & $15 \%$ & 1 & $5 \%$ & 1.111 & 0.292 \\
\hline
\end{tabular}

to the pathogenesis of POI, including physical manipulation of the bowel, surgical stress, inflammatory mediators, changes in electrolyte, neural reflux, pharmacologic agents such as inhalation anesthetics and use of opioids for postoperative analgesia. ${ }^{11}$ 
Traditionally, tolerance of oral feeding is based on the passage of flatus. However, the physiology of postoperative ileus suggests that such an approach is excessively conservative. It has been shown that paralysis of the small bowel is transient; the gastric paralysis lasts 24h and paralysis of the colon lasts 48-72h. ${ }^{12}$

This study has been conducted to evaluate the safety and tolerance of early oral feeding after small intestinal and colonic anastomosis.

Difronzo et al. prospectively analyzed 200 patients during a 5-year period and demonstrated that $>80 \%$ of patients tolerated early oral feeding after colonic surgery. Nicholas et al. reported that $72 \%$ of his patients tolerated early oral feeding without sequelae. 13

Marik and Zaloga conducted a metaanalysis of prospective randomized studies comparing early versus late enteral feeding and demonstrated the benefits of early nutrition. ${ }^{14}$

Andersen et al. conducted a systematic review of 13 randomized trials totaling 1173 patients undergoing gastrointestinal surgery. There were no significant difference between restricted and early postoperative diets but the findings also suggested that there was no advantage to dietary restriction. ${ }^{15}$

In our study, early feeding was started in group II patients and oral feeding was tolerated with low morbidity following small or large bowel resections and was not associated with occurrence of significant increase in anastomotic dehiscence.

Asignificant relative reduction in the risk of infection of any type was observed for patients receiving early enteral nutrition. Changes in intestinal permeability have been shown in patients undergoing gastrointestinal surgery, increased permeability being associated with sepsis and systemic inflammation. Bacterial translocation has also been shown in patients undergoing laparotomy, and a higher proportion of patients with bacterial translocation developed sepsis than those without. Early postoperative luminal nutrition might have a beneficial effect on the function of the intestinal barrier in respect of permeability, bacterial translocation and the subsequent development of septic complication. ${ }^{16}$

Villalba et al. reported that many prospective randomized studies showed that early feeding decreases postoperative ileus duration and hospital stay without increasing morbidity or mortality. Early feeding also reduces all risks of infection, as well as any anastomotic leak. ${ }^{17}$

Nicholas et al, reported that early oral feeding in fast track programs after colorectal surgery decreased general complications from $20-30 \%$ to below $10 \%$, while postoperative hospital stay was reduced from 10 days to 2-5 days.

De Aguilar Nascimento et al. ssuggested that early oral feeding in patients submitted to intestinal anastomosis is not only safe but also not associated with the occurrence of anastomotic dehiscence, and moreover, is related to quicker resolution of ileus. ${ }^{1}$

Takala et al. did not find changes in the incidence of intestinal anastomotic leakage when comparing the periods before and after the use of early enteral nutrition. ${ }^{18}$

Previous studies have shown a reduction in the incidence of septic complications and shorter hospital stay compared with controls when early enteral nutrition was used. ${ }^{19}$

Kudsk et al. randomized patients with abdominal trauma to enteral or parenteral nutrition and found that patients on EN developed less pneumonia, abscesses and sepsis, with a fewer number of infections per patient than the group on TPN. Moore et al. concluded that there is a positive effect on the reduction of septic complications when EN is used in comparison with TPN. ${ }^{3}$

The benefit of postoperative enteral feeding in surgical patients is that it reduces nutritional deficit that predisposes patient to developing complications, including deficits in the muscle function and surgical fatigue. Early oral feeding can preserve body organ functions rather than the usual postoperative deterioration in pulmonary function, body composition and cardiovascular response to exercise. $^{9}$ 


\section{Conclusion:}

Early oral feeding after gastrointestinal anastomosis in safe and can be tolerated by the majority of patients. It lowered general and local complications and reduced the duration of hospital stay. Thus, it may become a routine feature of postoperative management.

\section{Reference:}

1- El-Nakeeb A, Fikry A, El Metwally T, Fouda E, Youssef M, Ghazy H, Badr S, Khafagy W, Farid M: Early oral feeding in patients undergoing elective colonic anastomosis. International Journal of Surgery 2009; 7: 206-209.

2- Joon SP, Hye K C, Hokyoung H, Jae KK, Dong S: Postoperative nutritional effects of early enteral feeding compared with total parental nutrition in pancreaticoduodenectomy patients: A prospective randomized study. $J$ Korean Med Sci 2012; 27(3): 261-267.

3- Velez JP, Lince LF, Restrepo JI: Early enteral nutrition in gastrointestinal surgery: A pilot study. Nutrition 1997; 13(5): 442-445.

4- Hoover HC, Ryan JA, Anderson EJ, Fisher JE: Nutritional benefits of immediate postoperative jejunal feeding of an elemental diet. Am J Surg 1980; 139(1): 153-159.

5- Sosuke T, Hideo T, Junya F, Ryota M, Osamu I, Nobuhiro O: Early postoperative oral intake accelerates upper gastrointestinal anastomotic healing in the rat model. Journal of Surgical Research 2011; 169: 202-208.

6- Petrelli JN, Cheng C, Driscoll D: Early postoperative oral feeding after colectomy: An analysis of factors that may predict failure. Ann Surg Oncol 2001; 8: 796.

7- Lewis SJ, Egger M, Sylvester PA, Thomas S: Early enteral feeding versus "nil by mouth" after gastrointestinal surgery: Systematic review and meta-analysis of controlled trials. BMJ 2001; 323(7316): 773-776.

8- Malhotra A, Mathur AK, Gupta S: Early enteral nutrition after surgical treatment of gut perforations: A prospective randomized study. J Postgrad Med 2004; 50(2): 102-06.

9- Bahram M, Soltan H, Balbaa MA: Early versus traditional delayed oral feeding after small intestinal and colonic anastomosis. Ain-Shams J Surg 2010; 3(2): 125-130.

10- Argov S, Goldstein I, Brazilai A: Is routine use of the nasogastric tube justified in upper abdominal surgery? Am J Surg 1980; 139(6): 849-850.

11- Holte K, Kehlet H: Postoperative ileus: Progress towards effective management. Drugs 2001; 62: 2603-2615.

12- Rothnie NG, Harper RA, Catchpde BN: Early postoperative gastrointestinal activity. Lancet 1963; 2: 64-67.

13- Dipronzo LA, Cymerman J, O' Connell TX: Factors affecting early postoperative feeding following elective open colon resection. Arch Surg 1999; 134: 941-946.

14- Marik PE, Zaloga GP: Early enteral nutrition in acutely ill patients: A systematic Review. Crit Care Med 2001; 29(12): 2264-2270.

15- Andersen HK, Lewis SJ, Thomas S: Early enteral nutrition with $24 \mathrm{~h}$ of colorectal surgery versus later commencement of feeding for postoperative complications. Cochrane Database Syst Rev 2006; (4): CD004080.

16- O'Boyle CJ, Macfie J, Mitchell CJ, Johanstone D, Sagar PM, Sedman P: Microbiology of bacterial translocation in humans. Gut 1998; 42(1): 29-35.

17- Villable FF, Bruna EM, Garcia CM, Gacia RJ, Roig V V: Evidence of early oral feeding in colorectal surgery. Rev Esp Enferm Dig (Mad) 2007; 99(11): 709-713.

18- Takala J, Havia T, Heinonen R, Renvall S: Immediate enteral feeding after abdominal surgery. Acta Chir Scand 1985; 151: 143.

19- Moore FA, Moore EE, Jones TM, Mc Croskey B, Peterson VM: Total enteral nutrition versus total parenteral nutrition following major abdominal trauma-reduced septic morbidity. J Trauma 1989; 29: 916-911. 